\title{
LA POBREZA COMO INJUSTICIA (DWORKIN V. CALABRESI) ${ }^{1}$
}

0

Introducción. En un trabajo reciente ${ }^{2}$ me ocupé de la discusión entre Ronald Dworkin y Richard A. Posner sobre la eficiencia o, más exactamente, sobre la maximimización de la riqueza como criterio de eficiencia, criterio que, por otra parte. se afirma que el Derecho -o buena parte de él- satisface y/o debe satisfacer. Esta es justamente la pretensión de un sector del movimiento o escuela denominado «análisis económico del Derecho» (el sector encabezado por Posner) ${ }^{3}$. Advertí entonces que existe otro sector bien definido dentro de este mismo movimiento (el sector encabezado por Guido Calabresi) ${ }^{4}$ cuyas tesis fundamentales no coinciden con las del anterior. Este sector ha sido denominado «débil», «moderado» o «modesto» (si hacemos extensivo el calificativo aplicado por Dworkin a una de sus principales tesis) frente al carácter «fuerte», «radical» o «inmodesto» que cabe predicar de aquel otro. Pero este sector moderado ha sido objeto también de las críticas de Dworkin, y relatar y analizar estas críticas constituye

Mi agradecimiento a los profesores Juan Carlos Bayón y Alfonso Ruiz Miguel que leyeron el borrador de este trabajo y me hicieron útiles observaciones para mejorarlo.

${ }^{2}$ Liborio L. Hierro, «Contra el imperio de la riqueza (Dworkin v. Posner)», en Ronald Dworkin. Estudios en su homenaje, Revista de Ciencias Sociales, $n^{\circ} .38$, Edeval, Valparaíso, 1993, págs. 383-411.

${ }^{3}$ Este sector cuenta, entre sus más significativos representantes, con G. Becker, H. Demsetz, F. H. Easterbrook, I. Ehrlich, M. Landes y G. Tullock. Puede considerarse, sin duda, la corriente mayoritaria (Torres 1987, pág. 71 y Mercado 1994, págs. 58-64).

${ }^{4}$ Forman parte de este sector -junto a Calabresi- B. Ackerman, P. Bobbit, E. J. Mishan o A. M. Polinsky. La posición crítica que les caracteriza, frente al sector mayoritario, hace difícil encasillarlos. Tengo la impresión de que algunos de ellos aceptarían haber hecho «análisis económico», pero no pertenecer a la escuela del «Análisis económico». Es claro, por ejemplo, el distanciamiento de Ackerman (Ackerman, 1988, págs. 120-123 y, en particular, nota 16 en pág. 135). 
el propósito de este artículo que se convierte así en una especie de continuación de aquél. Me parece conveniente hacer una advertencia preliminar, provocada por alguna discusión suscitada en torno al trabajo anterior ${ }^{5}$. Se refiere al ámbito de las críticas de Dworkin al Análisis Económico del Derecho, al menos tal y como yo las entiendo. Estas críticas se mueven -en principio- en el nivel de los «fundamentos» filosóficos y presupuestos axiológicos del análisis económico. Tales fundamentos y presupuestos no sólo están implícitos, sino que han sido objeto de expresas «incursiones» por parte de los autores más representativos $^{6}$. La crítica no pone en cuestión, ni para afirmar ni para negar, la virtualidad científica o técnica de hacer análisis económico del Derecho (la ausencia de mayúsculas y negrilla pretende ser ahora plenamente significativa). No niega, por tanto, la «legitimidad» académica de este tipo de análisis ni su utilidad político-jurídica. Cuestiona sólo las implicaciones filosófico-jurídicas, en un sentido estricto, de la escuela que ha adoptado como nombre propio el de esa posible actividad (el Análisis Económico del Derecho ${ }^{7}$ ), es decir: cuestiona las relaciones entre eficiencia y justicia (los economistas suelen hablar, más modestamente, de «equidad $»^{8}$ ) en este análisis o, lo que es igual, la concepción implícita o explícita que

${ }^{5}$ Debo expresar mi agradecimiento al profesor Albert Calsamiglia por su invitación a presentar el trabajo citado en el Seminario de Profesores de Filosofía del Derecho, moral y política de la Universidad Pompeu Fabra, en Barcelona, el pasado mes de enero; igualmente al profesor Santos Pastor, del Departamento de Economía de la Universidad Carlos III de Madrid, por su atenta acogida y sus observaciones críticas y por invitarme a discutirlo, posteriormente, en el Seminario sobre «Economía y Derecho» que allí dirige.

${ }^{6}$ Como dice Kronman (1980, pág. 227) en referencia a dos trabajos de Posner: «taken together, these two articles represent Posner's only extended foray into the field of moral philosophy...». Posner ha insistido luego en sus incursiones en este campo. Respecto a Calabresi, los trabajos más significativos en este aspecto son -a mi entender- los siguientes: About Law and Economics: A Letter to Ronald Dworkin (1980) y The New Economic Analysis of Law: Scholarship, Sophistry or Self-indulgence? (1983), aunque las referencias a los fundamentos y a los límites ético-políticos del análisis económico son, en sus obras, constantes.

${ }^{7}$ Aunque no me parece de especial utilidad, puede verse una detallada y un poco prolija discusión sobre los nombres que este movimiento o escuela ha recibido en el trabajo de Pierluigi Chiassoni, Analisi economica del diritto, formularismo, realismo (1990), págs. 30-39.

${ }^{8}$ Ver, por ejemplo, A. M. Polinski que afirma: «el término eficiencia alude a la relación entre los beneficios totales de una situación y los costes totales de la misma, el término equidad alude a la distribución de la renta entre los individuos. En otras palabras, la eficiencia se relaciona con «el tamaño del pastel», mientras que la equidad dependerá de cómo se reparta». (Polinski, 1985, pág. 19). También Pastor (1989, pág. 34) señala que «la noción de equidad empleada en Economía es tomada de la Filosofía y se asocia con la noción de Justicia». Polinski señala, sin embargo, 
manejan sobre los fines del Ordenamiento Jurídico. Es claro, sin embargo, que este ámbito de cuestiones podría influir en aquél que -en principio- no se discute en la medida en que se llegase a la conclusión de que hay que sustraer parte o partes o, eventualmente, la totalidad del Ordenamiento Jurídico a las pretensiones descriptivas (positivas) y/o a las pretensiones normativas de tal análisis económico, para reducirlo a un papel vicario o meramente instrumental. Esta aclaración me parece importante, en todo caso, pues en alguna discusión he percibido una especie de posición defensiva de los economistas que parecían sentir atacada su legitimidad científica por críticas como las de Dworkin'. Para decirlo en pocas palabras, creo que el motivo de esta discusión no es tanto atacar el territorio de los economistas como defenderse contra su pretensión de invadir el territorio de los juristas o, como mínimo, contra cierto tipo de invasión: la de aquellos que han elaborado una teoría completa y pretenciosa, según la cual maximizar la riqueza (aumentar el tamaño del pastel) es el criterio de la eficiencia, la eficiencia es el criterio de la Economía, y la Economía -parece pretender- es el criterio del Derecho.

La atención del profesor Calabresi a este «nuevo» método es coetánea con su mismo nacimiento y puede ser considerado, por ello, uno de sus fundadores. Si aceptamos como fecha de nacimiento la de 1960, en que Coase publica The Problem of Social Cost, lo cierto es que en 1961 Calabresi publica Some Thoughts on Risk Distribution and the Law of Torts y él mismo ha alegado que estas reflexiones nacieron con independencia de la publicación de Coase, que

que este concepto económico de «equidad» no incluye el sentido en que el término es utilizado por filósofos y juristas donde se incluyen los procesos por los que se adquiere la riqueza, así como la protección de determinados derechos (ibídem, nota 2). Esta distinción entre «equidad» en sentido económico estricto $\mathrm{y}$ «equidad» $\mathrm{o}$ «justicia» como un valor más amplio tiene bastante importancia para la discusión subsiguiente.

${ }^{9}$ Torres López señala que «las críticas efectuadas al Análisis Económico del Derecho por su pretendido afán «imperialista» o bien son manifestaciones más bien poco justificadas de lo que Kirchner llama el «tradicional recelo del jurista al diálogo interdisciplinar» (cit. Paz, 1981, pág. 694) o bien suelen formar parte de una crítica más general y rigurosa de los planteamientos que derivan de la íntegra asunción del modelo neoclásico y de ahí que Posner, como su más preclaro representante, se convierta en eje prácticamente exclusivo de las mismas» (Torres, 1987, pág. 92).

Creo que, efectivamente, el objeto de las críticas de Dworkin es, principalmente, una cierta utilización «filosófica» (en el sentido de «globalizadora») de un cierto modelo, el modelo neoclásico.

Sobre el llamado «imperialismo» de la Economía ver también Torres 1987, págs. 89-92, Paz Ares 1981, pág. 689 y -muy especialmente- el más detallado análisis de Mercado 1994, págs. 75-125. Un trabajo al que se hacen frecuentes referencias es el de R. Brenner, Economics. An Imperialist Science (1980). 
habría luego de convertirse en punto de partida de la nueva escuela ${ }^{10}$. En conjunto esta nueva escuela se presenta como un enfoque distinto al del «antiguo» análisis económico: el antiguo o «viejo» análisis económico del Derecho sería aquél que se desarrolló en los años veinte y treinta y que se mantiene en vigor de forma incontrovertida, aunque con un alcance muy limitado: sería -en palabras de Calabresi- el análisis económico aplicado a situaciones en que la legislación se propone satisfacer ciertos objetivos económicos bien definidos. «El análisis económico se usaba entonces para determinar si sub-reglas específicas del common-law o legisladas servían para alcanzar los objetivos establecidos... la única función del análisis económico era la función vicaria de ver en qué medida estos valores»-de carácter económico, pero legalmente establecidos- «se estaban alcanzando en la práctica por las reglas secundarias y la legislación» (Calabresi, 1983, pág. 86). Por el contrario, el «nuevo» análisis económico se plantea utilizar los métodos de la economía para explicar y criticar las normas jurídicas incluso cuando no tienen un origen o un objetivo explícitamente económico ${ }^{11}$.

El nuevo análisis económico del Derecho parece ser el mismo tiempo un cierto desarrollo del realismo jurídico norteamericano ${ }^{12} \mathrm{y}$, metodológicamente, un sucedáneo del materialismo marxista en cuanto concibe la estructura subyacente del Derecho como exclusiva actividad económica, si bien con la notable diferencia de que el «paradigma» es el mercado como maximizador de la riqueza, la cual es el único criterio mensurable de la eficiencia económica ${ }^{13}$ al que -en la tesis mayoritaria de Posner- se reducen tanto las pretensiones

${ }^{10}$ Calabresi, 1991, pág. 1.213, nota 8, afirma: «Contemporaneously to, and independently of, the publication of Coase's The Problem of Social Cost, I published Some Thoughts...».

${ }^{11}$ Ver también, sobre «viejo» y «nuevo» análisis económico, Torres, 1987, págs. 15 y ss. y Paz Ares, 1981, págs. 609-613.

${ }^{12}$ Parece totalmente acertada la apreciación de Horwitz ( 1980, pág. 905) en el sentido de que «Law and Economics emerges to fill the intellectual vacumn left by Legal Realism. It is one of the many responses to the Realist critique of all attempts to create a completely autonomous and internally consistent realmof 'pure law'». Allí mismo Horwitzestablece la comparación con el marxismo vulgar, a la que a continuación hago alusión. Véase también, sobre la relación entre Análisis Económico y Realismo, Mercado 1994. Capítulo 4 y, en particular, pág. 204 («El AED ha sido considerado como heredero de la vertiente del realismo denominada -policy science- o -scientificbranch-, en tanto que expresa un intento por reconstruir una teoría objetiva y realista del análisis legal desarrollada a partir de los instrumentos proporcionados por la ciencia económica»).

${ }^{13}$ Uno de los más radicales defensores de Posner, en cuanto a la cuestión que vamos a analizar, es Johnsen, quien sostiene que la riqueza no sólo es un valor, sino que es «el único componente de valor social» (Johnsen, 1986, pág. 266). Para sostener esta tesis Johnsen incluye en el concepto de riqueza «todas las cosas valiosas que 
utilitaristas como los valores mayoritariamente aceptados. Calabresi, sin embargo, ha desarrollado toda su obra durante las tres últimas décadas marcando -creo que cada vez de forma más firme- sus diferencias respecto a las pretensiones de Posner tanto a nivel descriptivo como a nivel normativo ${ }^{14}$. Y estas diferencias son tan relevantes que hacen dudar sobre la unidad de la escuela.

1. Calabresi v. Posner o los límites éticos del análisis económico. Las críticas de Calabresi a Posner pueden, en mi opinión, enunciarse en cinco postulados y ello prescindiendo de otras diferencias relativas a diversas aplicaciones del análisis mismo (responsabilidad por accidentes, por ejemplo) y limitándome a cuestiones de fundamento. De forma clara podrían formularse así: (1) el Análisis Económico del Derecho posneriano, como pretendida teoría descriptiva, es una sofistería; (2) el Análisis Económico del Derecho basado en el criterio de maximización de la riqueza no es, ni descriptiva ni normativamente, neutro; (3) el criterio de maximización de la riqueza, como criterio normativo, no puede resolver el problema de la asignación inicial de puntos de partida; (4) el volumen de riqueza, sin tomar en cuenta su distribución, no es un valor; (5) el Análisis Económico del Derecho, aun asumiendo un intercambio entre maximización de la riqueza (eficiencia) y su distribución (equidad), no es un modelo normativo exhaustivo porque junto al binomio eficiencia-equidad existen otros valores (justicia) de carácter superior.

(1) Calabresi niega una de las tesis centrales del análisis posneriano: que el Common Law, ha obedecido, aun de forma inconsciente, al criterio de maximización de la riqueza ${ }^{15}$. Uno de los argumentos más poderosos del análisis posneriano reside, en efecto, en el

son escasas», lo que incluye «desde las tangibles más mundanas, como cañones y mantequilla, a las intangibles más metafísicas, como la «realización de las capacidades humanas exclusivas de cada uno» (ibídem, pág. 269). Sin embargo, en una perfecta ortodoxia posneriana, Johnsen admite que «not all valued things that are scarce are measurable. Those that are measurable can be viewed as the empirical componets of wealth. To test the positive hypothesis of wealth maximization it is neccessary to measure wealth in different states of the world. Dollars or dollar equivalents provide a convenient way of expressing the measurement» (Ibídem, pág. 270). Nótese que, entonces, las cosas intangibles y metafísicas que incluía en su noción de riqueza sólo forman parte de ella siempre que -y en la medida en que- usted las traduzca a dólares.

${ }^{14}$ Sobre el doble aspecto, descriptivo y normativo, del Análisis Económico del Derecho ver las referencias en Hierro 1993, pág. 389, nota 4.

${ }^{15}$ Sobre el significado del criterio de maximización de la riqueza, y su crítica, me remito a Hierro 1993, págs. 395 y ss. Entre las muchas formulaciones del aspecto descriptivo de la teoría en Posner, pueden verse estas dos (que no son exactamente 
aspecto positivo o descriptivo de la Teoría que, según se pretende, permite descubrir una especie de ley histórica subyacente en la evolución del Common Law. Calabresi no es, desde luego, el único que niega semejante pretensión descriptiva, pero no es tampoco el más tímido de los críticos: la afirmación constituye -según él- simple y llanamente una «sofistería» (Calabresi 1983, pág. 87). El carácter sofístico de esta pretensión es doble. En primer lugar, porque es imposible definir en qué consiste la riqueza si no conocemos los puntos de partida: «la riqueza en cualquier sociedad depende de los gustos, de lo que la gente quiere, de lo que ellos valoran. Pero lo que ellos valoran depende de lo que tienen para empezar. Si no tengo nada, valoraré el alimento, si tengo alimento puede que desee el sexo, si tengo ambos puede que codicie el Derecho, y si tengo el Derecho puede que desee el silencio» (ibídem, pág. 90) ${ }^{16}$. En consecuencia, afirmar que el Common Law maximiza la riqueza es ignorar su papel previo en establecer y cambiar los puntos de partida que son los que nos permitirán definir la riqueza (ibídem, pág. 91). En segundo lugar, porque la pretensión descriptiva parece conducir a la falacia naturalista en su utilización más conservadora: «sólo hay un pequeño paso desde la pretensión «positiva» de que el Common Law ha servido siempre a la maximización de la riqueza hasta la aserción normativa de que el objeto del Common Law debería ser la maximización de la riqueza» (ibídem, pág. 87). En esta primera crítica a las pretensiones descriptivas del análisis posneriano Calabresi coincide con muchos otros, aunque me interesa señalar que, entre ellos, coincide con Dworkin, como el mismo Calabresi reconoce expresamente ${ }^{17}$.

coincidentes): (a) «law can best be understood in wealth-maximizing and rent-seeking terms, the former being the demain of common-law, the latter of statute law» (Posner 1990, pág. 362): (b) «I am associated with several top-down theories. One, which is primarily positive (descriptive), is that the common-law is best understood en the «as if» assumption that judges try to maximize the wealth of society» (Posner 1992, pág. 433). Me parece curiosa la diferencia porque rara vez incluyen el Derecho legislado en el propósito descriptivo de la teoría y, en su aspecto normativo, es una de las cuestiones centrales en el debate -y resueltas con poca claridad por el mismo Posner- si la legislación también debe obedecer al criterio de maximización de la riqueza o puede asumir criterios de distribución.

${ }^{16}$ Ver también Calabresi 1972, pág. 48 («what is a Pareto optimal, or economically efficient, solution varies with the starting distribution of wealth. Pareto optimality is optimal given a distribution of wealth, but different distributions of wealth imply their own Pareto optimal allocation of resources») y Calabresi 1980, págs. 554-555 («That without starting points -wether termed rights, entitlements, bodily security, or what have you- it is hard to give any meaning to the term 'an increase in wealth'»).

${ }^{17}$ Calabresi 1983, pág. 91 , nota 1, y Calabresi 1980, pág. 554. Me parece destacable que estas críticas no hayan sido objeto de consideración por Posner en el apar- 
(2) El segundo postulado ataca una de las más fuertes pretensiones del análisis posneriano: el carácter científico y, por lo tanto, neutral del principio de maximización de la riqueza que al mismo tiempo sirve para explicar la estructura subyacente del Common Law (y, ocasionalmente, del derecho legislativo) ${ }^{18}$ y para proponer un criterio de decisión judicial ( $y$, eventualmente, de decisión legislativa $)^{19}$ que neutraliza las preferencias ideológicas. Esta posición va estrechamente ligada a una concepción naturalista de la verdad científica y a una autoafirmación de que la Economía es precisamente la más «científica» de las ciencias ${ }^{20}$. Ha sido probablemente Horwitz quien con más claridad ha denunciado ese trasfondo cientifista: «El Análisis Económico del Derecho es sólo la más reciente pretensión de apoyarse en el prestigio de las ciencias naturales en el esfuerzo para crear un sistema de pensamiento jurídico que sea objetivo, neutral y apolítico» (Horwitz 1980, pág. 905). Calabresi es también consciente de las pretensiones de neutralidad científica y del sofisma que encubren. A nivel descriptivo porque -como acabamos de ver- esconden la función fundamental del Derecho en atribuir o cambiar puntos de partida; a nivel normativo porque, pese a los intentos paretianos o posnerianos, resulta imposible eludir las comparaciones interpersonales lo que nos introduce «en un mundo completamente normativo donde la identidad y el mérito de los ganadores y perdedores se hace esencial. Permítanme ser claro -añade Calabresi-. El mundo normativo es en

tado que dedica a «Criticisms of the Positive Theory» en Posner 1990, págs. 362 y ss.

${ }^{18}$ Ver supra nota 15.

${ }^{19}$ No es claro tampoco Posner respecto a si la maximización de la riqueza es sólo un criterio de decisión para los jueces o también para el legislador; en unas ocasiones parece haber distinguido una cierta «división del trabajo» que atribuye al legislativo tareas de distribución, sin embargo creo que a la postre se inclina por extender la fuerza normativa de este principio también a la actividad legislativa (ver Hierro 1993, pág. 408). Respecto a la actividad judicial, Posner afirma que la maximización de la riqueza les permite tomar decisiones incontrovertibles: «this may be the only social policy that the tools of the judicial process enable judge to promote in a consistent and reasonably unocontroversial fashion; if so, wealth maximization offers judges a comfortable as well as socially useful guidepost» (Posner 1990, pág. 372).

${ }^{20}$ La cuestión tiene un particular desarrollo en Posner 1990, págs. 362 y ss., donde, por ejemplo, aparecen estas afirmaciones: «Economists pride themselves on being engaged in a scientific endeavour» (pág. 362); «these points suggest that economics is weak in comparison with the natural sciences, although it is the strongest of the human sciences» (pág. 366); y, en referencia a actividades científicas como la Sociología del Derecho, la Psicología del Derecho, la Antopología Jurídica o la Teoría del Derecho como teoría positiva (el subrayado es mío), afirma: «these fields of interdisciplinary studies, and other that could be named, are older than economic analysis of law yet are weaker candidates for a leading role in fashioning a positive thoery of law» (pág. 367). 
el que vivimos, y podemos decir mucho sobre lo que es bueno y lo que es malo en él. Lo que no podemos hacer, sin embargo, es esconder lo que está metido en ese mundo tras un criterio interpersonalmente neutro y actuar como si no estuviéramos haciendo juicios morales, cuyos efectos imponemos luego sobre otros» (Calabresi 1991, pág. 1.217).

Aunque no voy a extenderme sobre ello, conviene recordar que el principio posneriano de maximización de la riqueza es una reconstrucción (o aplicación simplificada) del criterio de Kaldor-Hicks ${ }^{21}$, que se justifica sobre la base de un consentimiento anterior de todos los participantes (Posner 1980, págs. 85-86), es decir que supone que todos han aceptado el principio de maximización de la riqueza -aunque un determinado incremento de la riqueza social suponga para ellos una pérdida sin compensación- porque están compensados ex-ante por la expectativa de que tal aumento les hubiera beneficiado (o, quizá, por la expectativa de vivir en una sociedad cuya riqueza se incrementa continuamente) ${ }^{22}$. Esta formulación permite prescindir de quiénes sean, en una situación dada, los ganadores y los perdedores, y convertir así la maximización de la riqueza en un criterio neutral.

Calabresi ha dedicado bastante atención a negar la realidad de este hipotético consentimiento y a demostrar que, por el contrario, sólo un criterio de optimalidad paretiana estricta sería neutral, aunque es impracticable, mientras que el criterio de Kaldor-Hicks -y por tanto su formulación como maximización de la riqueza- implica siempre redistribuciones, porque siempre hay ganadores y perdedores. Otra cosa distinta es que, a veces, podamos considerar irrelevante quienes sean, en una situación dada, los ganadores y los perdedores y eso es precisa y únicamente lo que justifica dejar cierto número de transacciones a la dinámica del mercado: no que no existan ganadores y perdedores, ni que todos hayan supuestamente consentido antes en perder, sino que para la atribución de ciertos derechos puede resultar indiferente, en efecto, quiénes sean los ganadores y quiénes sean los perdedores. «El argumento para permitir intercambios «libres» cuando lo hacemos (y en modo alguno los permitimos siempre) no es

${ }^{21}$ Sobre las formulaciones del criterio de eficiencia hasta llegar al de maximización de la riqueza adoptado por Posner y su escuela, ver Hierro 1993, págs. 385-396.

${ }^{22}$ Ver Hierro 1993, págs. 394-395, para una explicación más técnica de lo que Posner entiende como compensación ex-ante. Económicamente, significa que el precio (por ejemplo, de un solar) ya incluye la probabilidad o la imposibilidad de alteraciones futuras en su valor (en el ejemplo, de que puedan o no construir al lado una fábrica contaminante). Sin embargo, en el texto he generalizado, un poco toscamente, el argumento posneriano en la medida en que él mismo utiliza este criterio «económico» de compensación anticipada para convertirlo en criterio «filosófico» de justificación del principio de maximización de la riqueza. 
-como la gente suele decir estúpidamente- que no hay perdedores como resultado de los intercambios libres. Más bien es que se ha hecho un juicio distributivo consistente en que no nos preocupan los perdedores lo suficiente como para privar a los ganadores de su potencial ganancia. Desde luego, cuando nos preocupamos por los perdedores estamos listos para prohibir el intercambio... Y estamos listos para prohibir el intercambio si creemos que los perdedores en la transacción caen desproporcionadamente en categorías, como los pobres o los ancianos, sobre las que la sociedad tiene preocupaciones distributivas generalizadas» (Calabresi 1983, págs. 94-95) $)^{23}$.

(3) El tercer postulado es la proyección a nivel normativo del primer argumento que hemos visto sub (1). Si es imposible definir la riqueza prescindiendo de una asignación inicial de puntos de partida (de derechos), y si la función del Derecho es precisamente definir tales puntos de partida (derechos) y darles la protección correspondiente ${ }^{24}$, entonces el argumento posneriano de que el Derecho debe asignar los puntos de partida de tal forma que se maximice la riqueza social resulta una pretensión imposible: «Posner alega que los puntos de partida deberían asignarse de modo que maximicen la riqueza. Pero -concluye Calabresi- no hay forma de asignar puntos de partida de tal modo que pueda maximizarse lo que sólo dados ciertos puntos de partida puede ser definido» (Calabresi 1983, pág. 91) ${ }^{25}$.

${ }^{23}$ Más adelante Calabresi (1983, pág. 96) especifica esta crítica frente a la compensación ex-ante de Posner: «To assume consent in such a situation is implicitly to adopt a distributional theory which deems irrelevant the differences which would keep some people from consenting. This may be a good distributional theory or it may not, but it is a distributional theory, none the less, and its silent adoption cannot be sustained». Los mismos argumentos, con algún matiz, en Calabresi 1991, pág. 1.224: «Nor am I suggesting that Posner's distributional theory is always wrong. There may be situations in which winners and losers are random, or where the incidence of the change cannot be determined, so that we cannot know who the winners and the losers are. Then treating winners and losers as the same may well be justified. There may also be situations in which a just distributional theory leads to the conclusion that we are indifferent between the actual winners and the actual losers»».

${ }^{24}$ El artículo de Calabresi y Melamed Property Rules, Liability, Rules, and Inalienability: one View of the Cathedral (1972) es un brillante desarrollo de cómo, a partir de la asignación de derechos o posiciones iniciales que puede obedecer a criterios de eficiencia económica, o de preferencias distributivas o a otras razones de Justicia, el ordenamiento jurídico dispone de tres mecanismos distintos de protección de tales asignaciones iniciales: las reglas de propiedad, las reglas de responsabilidad y las reglas de inalienabilidad.

${ }^{25}$ En el mismo sentido Calabresi 1980, pág. 555 («It is hard to know what to make of a statement that maximizing wealth is a good thing, unless one has accepted something, other than wealth maximization, as a round for initial starnting points»). 
(4) «Después de todo, ¿quién se ha creído alguna vez que la maximización de la riqueza sin atender a su distribución pudiera tomarse como objetivo del Derecho o de una sociedad justa?» (Calabresi 1983, pág. 89). Calabresi considera que ésta nunca ha sido una pretensión del utilitarismo puesto que, aunque se le puede imputar la defensa de un máximo de felicidad sin atender a su distribución, un máximo de riqueza mal distribuida no conduce a un máximo de felicidad. En la Carta a Ronald Dworkin (1980, pág. 556), comentando la discusión Dworkin-Posner y refiriéndose al argumento posneriano de que la maximización de la riqueza promueve un conjunto de valores (las virtudes protestantes), afirmará: «La dificultad es que la maximización de la riqueza, prescindiendo de su distribución, no me parece a mí (y yo aseguraría que a casi nadie) que promueva el embrollo de metas que yo, más tolerante que tú, aceptaría».

(5) Finalmente, Calabresi niega que -incluso admitiendo un equilibrio entre eficiencia (incremento de la riqueza) y equidad (distribución de la riqueza)- la riqueza constituya por sí misma un objetivo valioso. Por el contrario sostiene -señalando aquí también su expreso acuerdo con Dworkin (Calabresi 1980, págs. 554 y 556)- que «incluso con un punto de partida, es difícil ver cómo un incremento en la riqueza constituye una mejora en una sociedad a menos que promueva algún otro objetivo, como la utilidad o la igualdad... el adelanto de eficiencia es, como tú dices, meramente instrumental y necesita ser añadido a algún balance de aquello para lo que es instrumento antes de que pueda evaluarse».

He resumido en estos cinco postulados las críticas de Calabresi, a mi entender más relevantes, a la corriente mayoritaria del Análisis Económico del Derecho. Lo que ocurre es que estas críticas, en el terreno de los fundamentos, parecen ser tan amplias y tan profundas -al poner en cuestión al mismo tiempo sus pretensiones descriptivas y su criterio normativo básico, la maximización de la riqueza- que uno se pregunta en qué consiste, entonces, el análisis económico defendido por Calabresi. Y también Calabresi mismo se hace esta pregunta: «¿Dónde deja esto al nuevo análisis económico del Derecho?» (Calabresi 1993, pág. 100).

La crítica de la «imposibilidad» ha sido también desarrollada por Dworkin (vid. Hierro 1993, págs. 403 y ss. donde traté de distinguir esta crítica de otra estrechamente conectada con ella que sería la de la «circularidad»: cuando Posner afirma que la maximización de la riqueza promueve ciertos valores y cierta asignación de derechos valiosa, resulta que tales valores o esa tal asignación de derechos son «valiosos» porque maximizan la riqueza). 
2. Las posibilidades del Análisis Económico del Derecho como programa constructivo. Fue el mismo Calabresi quien dijo que todos los críticos del Análisis Económico, sean marxistas, conservadores o radicales, llegan a la conclusión de que no se trata de otra cosa más que de una «tontería sobre zancos» (Calabresi 1983, pág. 85). A juzgar por sus críticas no está él muy lejos de pensar lo mismo en relación con Posner y su escuela, de cuyas tesis afirma -como hemos visto- que son «sofistería», «absurdas a primera vista» (ibídem, pág. 90), «vano intento de convertir la compulsión en consentimiento» (Calabresi 1991, pág. 1.223) y cosas semejantes. Ello no obstante Calabresi piensa que las perspectivas son sustancialmente distintas si el Análisis Económico del Derecho se aborda huyendo de toda tentación dogmática ${ }^{26}$ y asumiendo cierta responsabilidad académica sobre las cuestiones distributivas.

Voy a resumir también en cinco puntos las características que entiendo más relevantes en el proyecto analítico-económico de Calabresi, y en cinco puntos que son correlativos con las cinco diferencias críticas que le separaban del grupo mayoritario. Se trata, por supuesto, de una presentación meramente convencional que -me parece- pueda facilitar la comprensión de ambos modelos ${ }^{27}$. Podrían enunciarse así: (1) el Análisis Económico del Derecho es, a nivel descriptivo, un punto de vista más sobre el Derecho; (2) el Análisis Económico del Derecho tiene también una función valorativa (y normativa) instrumental para la creación y aplicación del Derecho; (3) la eficiencia puede ser un criterio relevante para configurar, criticar o modificar las leyes, (4) una mezcla apropiada de eficiencia (volumen de riqueza) y distribución no es lo mismo que la Justicia, pero es un instrumento para alcanzar la Justicia; (5) la Justicia es un valor diferente (al equilibrio entre volumen y distribución de la riqueza) y superior ya que tiene carácter final (no instrumental) y, por ello, capacidad de veto.

${ }^{26}$ En una intervención en Barcelona, en junio de 1984, Calabresi defendió matizadamente las acusaciones de dogmatismo contra el Análisis Económico del Derecho: «No estoy del todo de acuerdo con Tom Heller en que el método del análisis económico del Derecho haya llegado a este punto repudiable (convertirse en una dogmática) en los Estados Unidos. Con ello no quiero decir que no me preocupe y no sea crítico respecto del modo como ciertos autores de mi país lo emplean; pues considero que algunos lo hacen de un modo excesivamente dogmático, sin perjuicio de que a veces comparta los resultados que alcanzan» (1985. pág. 221).

${ }^{27}$ Otras presentaciones del enfoque de Calabresi, en castellano, pueden verse en Durán y Lalaguna 1992, cap. VI (págs. 121-136), Mercado 1994, págs. 239-245 y Torres López 1987, págs. 72-80. También un excelente balance de su obra en la Presentación de Joaquín Bisbal a la edición española de El Coste de los accidentes (1984. págs. 7-17). 
(1) La primera respuesta de Calabresi a la pregunta que -como hemos visto- él mismo dejaba planteada es que el Análisis Económico del Derecho tiene una función en el nivel del análisis descriptivo, aun prescindiendo de la aspiración a reinterpretar todo el Common Law bajo la «ley» de la maximización de la riqueza. Se trata, por un lado, de la posibilidad de encontrar explicaciones plausibles a ciertas doctrinas jurídicas y cambios legales a partir de determinadas estructuras (puntos de partida) y determinados objetivos distributivos propios de cada época. Es, principalmente, un análisis histórico esclarecedor que permite poner de relieve explicaciones institucionales que, de otra forma, resultan incomprensibles ${ }^{28}$. Por otro lado el análisis positivo puede también operar en sentido contrario: es decir, si se asume que ciertas leyes pretendían o pretenden la eficiencia en ciertos objetivos económicos, el análisis «puede ayudar a sugerir qué teorías distributivas, puntos de partida y presupuestos fácticos habrían sido necesarios» (Calabresi 1983, pág. 101) para obtener el resultado eficiente pretendido $^{29}$.

Pero esto no significa que el análisis económico sea «el» punto de vista que explica el Derecho (como, en relación al menos al Common Law, pretende el sector mayoritario); se trata sólo de «un» punto de vista. Con una imagen que ha hecho famosa el título de uno de sus trabajos más conocidos, cabe decir que se trata sólo de «una vista de la Catedral» ${ }^{30}$.

${ }^{28}$ Calabresi (1983, pág. 101) afirma que esa fue una de las primeras aportaciones del Análisis Económico y cita, como ejemplo, su obra ya clásica Some Thoughts on Risk Distribution and the Law of Torts (1961). Un buen ejemplo de este nivel de análisis positivo sería -en mi opinión- la discusión con Posner y otros autores en relación a los fundamentos de la responsabilidad objetiva a partir de la doctrina del juez Learned Hand, en Calabresi y Hirschoff, Toward a Test for Strict Liability in Torts (1972).

${ }^{29}$ No hace falta una gran experiencia en cuestiones de política jurídica para darse cuenta hasta qué punto este tipo de análisis es relevante. Suele decirse, por ejemplo, que la legislación arrendaticia española inspirada por el sector más «social» del régimen franquista consiguió resultados opuestos a los deseados. Los ejemplos podrían extenderse, en el pasado y en el presente. Una de las discusiones más frecuentes entre nosotros, durante los recientes años de crisis económica, ha sido si ciertas políticas intervencionistas con el objetivo de abaratar el suelo urbano disponible, e impulsar la industria de la construcción al mismo tiempo que ofrecer vivienda asequible a los jóvenes, no han resultado por el contrario en un incremento del valor del suelo al restringir la oferta. No pretendo con esto sino señalar que este nivel de análisis es obviamente -y no trivialmente- necesario.

${ }^{30}$ Calabresi y Melamed, Property Rules, Liability Rules, and Inalienabilitv: One View of the Cathedral (1972). La imagen, según explican en nota 2, se debe al profesor Harry Wellington que la utilizada en muchas discusiones jurídicas para indicar que -como en los cuadros de Monet de la Catedral de Ruán- «para comprender la Catedral uno debe verlos todos». El artículo de Calabresi y Melamed termina diciendo que «este enfoque también aporta sólo una vista de la Catedral». 
(2) El análisis económico no tiene por qué limitarse a esa contribución descriptiva. La venganza de Posner -dice Calabresi con tono de broma- sería fácil si, una vez criticada la falta de neutralidad de la maximización de la riqueza, nos limitáramos a decir que, en su lugar, sólo podemos ofrecer nuestras particulares preferencias (una posición «autocomplaciente») (Calabresi 1983, págs. 97-98). Pero el estudioso que -como antes vimos- no desea eludir que vive «en un mundo normativo» no tiene por qué limitarse a ofrecer, en lugar de criterios seudoneutrales, puras inclinaciones personales. Tiene que asumir la responsabilidad de ofrecer teorías distributivas que sean el resultado de sus conocimientos empíricos y de su habilidad filosófica: «Tal crítica del Derecho, abierta y normativa, basada en nociones académicas sobre la distribución podría ser, sin embargo, frecuentemente rechazada, pero no sería ni sofística ni auto-complaciente» (ibídem, pág. 99). $\mathrm{Si}$, por ejemplo, el análisis puede demostrar que en un cambio en el sistema legal de responsabilidad los perjudicados son los relativamente ricos, los de mediana edad y las familias numerosas, éstos son datos que el legislador desea conocer y la tarea académica no puede limitarse a ofrecer el resultado (científico) en términos de ganancia o pérdida neta, sino que será de gran ayuda si, junto a ello, analiza de forma clara quiénes serán los ganadores y quiénes los perdedores: «El académico, organizando un análisis económico combinado de pérdidas y ganancias con una teoría distribucional que diga para quién es preferible una ganancia neta o una pérdida neta, estaría facilitando sustancialmente la capacidad de los legisladores para reformar la ley» (ibídem, pág. 103).

(3) Puesto que la eficiencia no es, por sí misma, un valor y, mucho menos, un valor excluyente, cualquier ley eficiente puede ser criticada porque, por razones distributivas, es preferible otra ley ineficiente (ibídem, pág. 97); pero -hecha esta importante salvedadCalabresi reivindica lo que denomina una «proposición calabresiana» que ha sostenido a un sector del Análisis Económico durante años, a saber: «Siempre que, como consecuencia de un cambio legal, los ganadores ganen más de lo que los perdedores pierden y los efectos distributivos del cambio sean deseables o simplemente aceptables, entonces el economista-jurídico puede atacar efectivamente la ley existente» (ibídem, pág. 97). Desde luego que esta afirmación -que podríamos llamar «Teorema de Calabresi»- empieza a explicarnos de forma más contundente el alcance que, como teoría normativa, tiene para él el Análisis Económico ${ }^{31}$. Y ello es así porque la

${ }^{31}$ Resulta claro que, para Calabresi, el ámbito normativo del Análisis Económico tiene más importancia que su ámbito descriptivo. Torres López, creo que 
eficiencia mantiene alguna conexión necesaria para la propia idea de Justicia: «la eficiencia forma parte de nuestra noción de justicia, debido a que nos resultaría muy difícil sostener que un sistema que admitiera, abiertamente, el despilfarro, fuese justo» (Calabresi 1985, pág. 227).

(4) El problema central para el Análisis Económico reside, precisamente, en la distribución justa. Si partimos de que el volumen de riqueza, sin tomar en cuenta su distribución, no es un valor, la afirmación contraria es que el volumen de riqueza, con una distribución adecuada, sí es un valor o, al menos, es instrumento para alcanzar otros valores. Pero esta afirmación centra el problema en decidir cuál es la distribución deseable y cuál es la mezcla adecuada entre volumen de riqueza (eficiencia) y distribución, o -dicho en otros términos- qué sacrificios en eficiencia deben hacerse en aras de la distribución. Calabresi acepta -creo- que este es el desafío más importante: «No me malentiendan. Yo no sugiero que no podamos decir nada sobre la distribución justa. Mi posición es justamente la contraria... el fracaso del criterio de Pareto para servir como guía real hace inevitable una discusión abierta y continua sobre la distribución y las comparaciones interpersonales» (Calabresi 1991, pág. 1224). Años antes, en la Carta a Ronald Dworkin (1980), había sostenido (frente a la apreciación de Dworkin de que la cuestión estriba en saber si la justicia exige alguna redistribución a costa de alguna eficiencia): «Yo iría más lejos y diría que una mezcla apropiada de eficiencia y distribución es altamente instrumental para, y tiene una estrecha correlación con, conseguir lo que muchos verían como una sociedad justa» (Calabresi 1980, pág. 558). Por lo tanto, en este enfoque la función normativa del Análisis Económico no se resuelve bajo un sencillo principio unitario (maximizar la riqueza), sino que se complica notablemente: se trata de entrar en el mundo de lo valorativo o normativo para proponer una distribución justa de la riqueza, o una adecuada mezcla de eficiencia y distribución que formaría parte de nuestra idea intuitiva de justicia. Y, sin embargo, ello no significa que una distribución «justa» de la riqueza, o una mezcla adecuada de eficiencia y distribución, sean lo mismo que la justicia.

(5) En El coste de los accidentes (1984, original de 1970) ya

muy razonablemente, sitúa el enfoque de Calabresi en un capítulo que dedica a «Proposiciones normativas: crítica de la corriente eficientista» frente al capítulo anterior «Enfoque positivo: el desarrollo del postulado de eficiencia» en que sitúa la teoría de Posner (ver Torres 1987, capítulos III y IV). Ver también Mercado 1994, págs. 54 y 280. 
había señalado Calabresi que «la justicia es una función de naturaleza totalmente distinta de la reducción del coste de los accidentes» (esto es, de la eficiencia) (pág. 43) de forma tal que cualquier sistema de responsabilidad civil se propone dos funciones principales: la justicia y la reducción de los costes (es decir, justicia y eficiencia) (ibídem, pág. 42), pero estos dos objetivos son de distinto nivel, ya que la justicia «no es una función, sino un imperativo capaz de vetar sistemas o el uso de determinados instrumentos, o estructuras, en un sistema dado» (ibídem, pág. 43) ) $^{32}$ La justicia aparece, por tanto, como un límite para la eficiencia que puede incluso exigir sacrificios en ella ${ }^{33}$. Pero ¿qué es la justicia? Calabresi no proporciona una respuesta clara ${ }^{34}$. Insistirá, sin embargo, en que la justicia no es sólo una adecuada mezcla de riqueza y distribución y en que -como acabamos de ver-, aunque esta mezcla tiene un carácter instrumental y una estrecha relación con lo que muchos consideraríamos una sociedad justa, sin embargo «no garantiza una sociedad justa» (Calabresi 1980, pág. 559). Más recientemente Calabresi ha vuelto a presentar la justicia como un valor superior, aunque también de forma notablemente oscura. Llevar más lejos la intuición de Coase (que todos los mercados, actuales o potenciales, tienen costes) nos obliga -dice Calabresi- a plantearnos la «penúltima» cuestión sobre qué conductas permiten, con menor coste, mover la frontera del óptimo paretiano y quién ganará o perderá con ello (Calabresi 1991, pág. 1.237). Pero resulta que ésta es la «penúltima» pregunta porque «aunque está íntimamente vinculada a la justicia, para algunos de nosotros, al menos, no puede ser la última; esa pregunta debe ser trascendental» (ibídem, pág. 1.237, nota 79).

${ }^{32}$ Ver también Calabresi 1984, pág. 323, nota 1 al Capítulo 3.

${ }^{33}$ Finalmente, la fórmula de la función principal del sistema de responsabilidad es, en consecuencia, «producir la máxima reducción de la suma del coste de los accidentes y del coste de evitarlos, mediante un medio que sea justo» (Calabresi 1984, pág. 48). Ver también ibídem, pág. 94 sobre los sacrificios de eficiencia en aras de valores «superiores».

${ }^{34}$ En Calabresi 1984, Capítulos 15 y 16, hay una vaga distinción entre el punto de vista de la comunidad (diríamos, la moralidad positiva) y el punto de vista crítico, pero ninguna aproximación al concepto. En Calabresi 1980. pág. 554 nota 1, manifiesta ciertas reservas ante la ambigüedad del término «justicia», aunque también rechaza como demasiado cerrada la formulación de Dworkin de la justicia como igualdad. Tampoco en Calabresi-Melamed 1972 la justicia, aun estando presente como un objetivo distinto a la eficiencia, queda bien definida; ni siquiera bien parada: «The final reasons for a society's choice of initial entitlements we termed other justice reasons, and we may as well admit that it is hard to know what contein can be poured into that term... those preferences which cannot be easily explained in terms of these relatively few broadly accepted distributional preferences, or in terms of efficiency, are termed justice reasons» (págs. 54 y 57). 
(3) Dworkin v. Calabresi: (I) Transacciones imposibles. En el breve pero enjundioso debate de Dworkin con Calabresi hay que distinguir dos momentos sucesivos ${ }^{35}$ en los que Dworkin se enfrenta a dos formulaciones distintas (o a dos interpretaciones distintas) de la relación entre eficiencia y justicia según Calabresi. En el primero, Dworkin entiende que Calabresi propone una teoría según la cual la eficiencia (como maximización de la riqueza) es un valor social aunque en concurrencia con otros.

Trazando un esquema general de las propuestas del Análisis Económico del Derecho, Dworkin señala que caben dos tipos -con diversos subtipos- de respuesta a la pregunta «¿Es la riqueza un valor?». Serían los siguientes: (1) que la riqueza social es un valor en sí misma ${ }^{36}$, ya sea (1.1) entendida como el único valor social o (1.2) entendida como un valor social entre otros; (2) que la riqueza social es instrumento de algún otro valor social, ya sea (2.1) porque es causa de otro u otros valores, (2.2) porque es ingrediente de otro u otros valores o (2.3) porque es sucedáneo de otro u otros valores (de tal modo que funciona como un falso-objetivo cuyo alcance implica correlativamente la consecución de otros objetivos valiosos) (Dworkin 1980, págs. 240-241). La primera interpretación de Calabresi le sitúa, en este esquema, en el supuesto (1.2), es decir, entre quienes sostienen que la riqueza social es un valor entre otros. La teoría modesta del Análisis Económico -como Dworkin la denomina- presupone la idea de que la riqueza es un valor entre otros porque sólo bajo esta suposición es posible hablar -como Calabresi parece hacerlo- de transacciones entre eficiencia y justicia. Calabresi, según Dworkin, había defendido que el Derecho de accidentes tiene dos fines, la justicia y la reducción de los costes, y que ambos fines pueden entrar en conflicto en cuyo caso se requiere una decisión política

\footnotetext{
${ }^{35}$ Dworkin en Is Wealth a Value? (1980) desarrolló una primera crítica al Análisis Económico del Derecho abarcando las versiones de Posner y de Calabresi. Este trabajo se publicó en 1980 en el Journal of Legal Studies $\left(\mathrm{n}^{\circ} .9\right)$ aunque había sido redactado el año anterior para las conferencias Cooley de la Universidad de Michigan, a las que Calabresi no pudo finalmente asistir. Tuvo, sin embargo. conocimiento del texto de Dworkin y le replicó en la «Carta a Ronald Dworkin» (1980), fechada el 29 de agosto de 1979, que se publicó al año siguiente en la Hofstra Law Reviev (no ${ }^{\circ}$ 8). En este mismo número, Dworkin publica Why Efficiency? (1980/2) en donde continúa desarrollando sus críticas, tomando ahora en cuenta las aclaraciones de Calabresi (sobre todo ello, ver Calabresi 1980, pág. 553 nota 1, donde además responde parcialmente a la segunda publicación de Dworkin). Dworkin ha dedicado también al Análisis Económico del Derecho el Capítulo 8 de Law's Empire (1986), donde reproduce las críticas que estamos viendo.

${ }^{36}$ Dworkin (1980, pág. 240) habla de «a component of social value» lo que define corno «algo que merece la pena tener por sí mismo» («that is, something worth having for its own sake»).
} 
que priorice el fin que, en cada caso, ha de prevalecer ${ }^{37}$. Esta idea -señala Dworkin- coincide con las frecuentes representaciones gráficas de curvas de indiferencia cuyos ejes expresan, respectivamente, la justicia o moralidad y la riqueza social o eficiencia (ibídem, pág. 246). La cuestión estriba en desentrañar el significado del eje que representa la justicia y que suele entenderse como una función de las elecciones individuales, pero esto, a su vez, puede ser interpretado de dos formas: elecciones individuales sobre la sociedad en que cada uno desearía vivir o elecciones individuales sobre la sociedad que cada uno considera moralmente mejor. En el primer caso, y asumiendo que los individuos piensen en términos de riqueza, y no de utilidad, no parece nada razonable suponer que elegirán, en condiciones de incertidumbre, una sociedad globalmente más rica (en la que ellos podrían no tener nada o muy poco), sino más bien suponer que elegirán algo más parecido al maximin rawlsiano ${ }^{38}$. En el segundo caso resulta misterioso -continúa Dworkin- afirmar que un individuo tiene que hacer transacciones entre justicia y riqueza, ya que, si sólo se trata de elegir un modelo de sociedad moralmente deseable, no se entiende por qué, entonces, «no sería la justicia la única cuestión» (ibídem, pág. 248). Responder que la justicia no es la única virtud social por lo que ha de combinarse con otras (como la cultura o la riqueza) o responder que han de hacerse transacciones entre el volumen global de riqueza y su deseable distribución porque ambos forman parte de la idea de justicia implica, en ambas respuestas, que la riqueza es en sí misma un valor: un valor independiente que compite con otros (cultura, justicia) o bien un elemento del valor «Justicia» que compite con otros elementos de ella. Y Dworkin sostiene que -como ya demostró- «es absurdo considerar a la maximización de la riqueza como un valor, dentro o fuera del concepto de justicia» (ibídem, pág. 248) ${ }^{39}$.

${ }^{37}$ Calabresi 1980, pag. 557, niega expresamente que haya sostenido esta tesis: «I do not find any passage in which I say that these goals may sometimes conflict so that a political choice is needed about which goal should be pursued. What I do say is quite different...»

38 «They would be better advised to choose something much closer to maximin of individual wealth, for example, which is Rawls' second principle... if their only choice were maximin or highest social wealth, they would certainly choose the former» (Dworkin 1980. p. 247).

${ }^{39}$ Ver Dworkin 1980, págs. 242-246 donde trata de demostrar, con el ejemplo DerckAmartya, que una sociedad más rica no es mejor que una menos rica; y Dworkin 1986, pág. 288: «So increasing social wealth does not in itself make the community better». Ver también Hierro 1993, págs. 397-399.

Dworkin (1980. pág. 249) rechaza también cualquier interpretación de estas elecciones entendiéndolas como elecciones de la sociedad en cuanto totalidad personificada, lo que considera «una estupidez». 
Un último argumento de Dworkin contra la idea de transacciones entre eficiencia y justicia se refiere a la concepción de la riqueza como instrumento. Si alguien sostiene esta tesis, en cualquiera de sus versiones, no puede hablar de transacciones entre riqueza y justicia porque no hay transacción alguna entre medios y fines.

«Ninguna de estas interpretaciones de la transacción entre justicia y riqueza tiene sentido -concluye Dworkin-. Espero que la idea, por otra parte familiar, desaparezca pronto de la teoría económica y política» (ibídem, pág. 249).

4. Dworkin v. Calabresi: (II) Entre el compromiso y la receta. La respuesta de Calabresi a las anteriores críticas de Dworkin sirvió para aclarar el alcance de sus propuestas en los dos aspectos que vimos antes bajo los puntos (4) y (5) del apartado 2, esto es: que la justicia es un valor diferente y superior a la eficiencia (por ejemplo, un sistema eficiente de reducción del coste de los accidentes podría ser rechazado por ser injusto) y que las transacciones se producen entre eficiencia y distribución (y no entre eficiencia y justicia). Pero Dworkin no se dio por satisfecho.

En el primer aspecto -al que no presta ahora mucha atención- Dworkin se remite a sus argumentos anteriores: afirmar que la justicia tiene poder de veto sobre la eficiencia supone entender que la eficiencia es un valor o un instrumento de un valor. Dicho en otras palabras, sólo cabe considerar a la justicia como un valor jerárquicamente superior a la eficiencia si la eficiencia tiene, en sí misma, un carácter valioso.

La segunda cuestión es la que aparece ahora como una formulación nueva: las transacciones se producen entre eficiencia (volumen de riqueza) y distribución. Esta propuesta, dice Dworkin, puede ser interpretada en tres sentidos.

(1) En primer lugar, podría interpretarse como un compromiso entre eficiencia y distribución igualitaria, pero esto implica que la eficiencia (el incremento del volumen de riqueza) continúa asumiéndose como algo valioso por sí mismo, ya que sólo caben compromisos «entre dos bienes o cualidades deseadas independientemente» (Dworkin 1980/2, pág. 267). Puesto que Calabresi ha aceptado expresamente que la maximización de la riqueza no es un valor ${ }^{40}$ es necesario desechar esta primera interpretación (ibídem, pág. 268).

${ }^{40}$ Calabresi 1980, pág. 556 propone -dando expresamente la razón a Dworkin- que la riqueza es «merely instrumental and needs to be attached to some account of what it is instrumental toward before it can he evaluated». Sugiere allí que ese otro fin al que la maximización de la riqueza sirve podría ser la utilidad o la igualdad. 
(2) La segunda interpretación es que se trata de una receta según la cual una determinada mezcla de ingredientes es correcta cuando da lugar al mejor producto final. En la receta, a diferencia del compromiso, los ingredientes no son deseados independientemente. Bajo esta interpretación cabría entender que Calabresi propone una receta de «la utilidad social máxima» (éste sería el producto) que se consigue combinando «algo menos de la mayor riqueza total con algo menos del modelo más igualitario posible» (ibídem, pág. 268). En tal caso, ni la riqueza ni la igualdad se valoran independientemente, sino como meros ingredientes que producirán, adecuadamente combina dos, la mayor utilidad total. Pero Dworkin cree que tampoco es ésta la propuesta de Calabresi, puesto que éste defiende la igualdad (una distribución igualitaria) como algo valioso.

(3) Una tercera interpretación consiste en entender que Calabresi propone un compromiso, pero un compromiso entre un modelo igualitario y la riqueza social entendida como sucedáneo de otro valor, a saber: la utilidad global. «El compromiso subyacente es entre la utilidad total y una distribución igualitaria» (ibídem, pág. 269) aunque, a efectos prácticos, aparezca como un compromiso entre la distribución igualitaria y la maximización de la riqueza (en la medida en que la maximización de la riqueza es sucedáneo, o falso-objetivo, de la utilidad). Una vez más, esta idea de compromiso sugiere que ambos objetivos -ahora, igualdad en la riqueza y utilidad total- son en sí mismos valiosos.

La crítica de Dworkin a esta tercera interpretación resulta, en mi opinión, indirecta y algo más confusa. Dworkin pretende ahora demostrar que, frente a un compromiso entre igualdad y utilidad global, resultaría más coherente -para quien comparte el valor de la igualdad- abrazar una teoría distinta: una receta de la igualdad. La teoría del compromiso exige adoptar parcialmente el utilitarismo (sólo parcialmente, para dejar sitio a los derechos, como Calabresi pretende) y adoptar un utilitarismo teleológico (el placer o la felicidad son un bien en sí mismo) y no un utilitarismo igualitario (que distribuye la utilidad para tratar a todos igual) porque sólo así puede valorar la utilidad global y convertirla en algo que debe transigir con otro valor, la igualdad. Frente a ello, una receta de la igualdad es una teoría que «no considera que la riqueza total o la utilidad total, de un lado, ni la igualdad en la riqueza, de otro, sean algo valioso en sí

Una formulación todavía más clara, en este sentido, en Calabresi 1991, pág. 1.223 nota 35: «The problem remains, however, that maximization of wealth has no independent social value. It cannot be acepted as a good in itself, without support front some moral-distributional theory». 
mismo» (ibídem, pág. 271). Un igual tratamiento, cuando toma en cuenta la responsabilidad de cada uno por sus propias decisiones, puede ocasionalmente conducir a movimientos hacia la igualdad en el reparto o a movimientos hacia el incremento de la riqueza, pero unos y otros son sólo el resultado del igual tratamiento. La teoría de la igualdad sostiene que la justicia «consiste en aquella distribución en que las personas son tratadas como iguales (o, si esto es distinto, en los incrementos paretianos de esa distribución) y niega que haya ningún valor independiente, al margen del juego de aquel cálculo, ya sea en la igualdad en la riqueza ya sea en el mayor agregado de riqueza o de utilidad» (ibídem, pág. 272). Entre esta idea de la receta de la igualdad y aquella teoría del compromiso hay dos importantes diferencias: la primera es que, para el «compromiso», la igualdad en la riqueza y la utilidad total son ambos objetivos valiosos por lo que su combinación es deseable en tanto permita mantener el máximo de ambos, mientras que, para la «receta», la mezcla es el objetivo primario y la igualdad en la riqueza o la utilidad total son sólo los ingredientes de un igual tratamiento a las personas; la segunda es que la justicia resulta, para el «compromiso», algo impersonal (los individuos son sólo instrumentos para conseguir cantidades agregadas de igualdad y de utilidad) mientras que, para la «receta», la justicia es una cuestión de trato personal (ibídem, pág. 272).

En definitiva, la pretensión de Dworkin es que no se hable más de transacciones: «Espero persuadir a Calabresi para que abrace una teoría de la receta de una igualdad-profunda en lugar de la teoría del compromiso y, en consecuencia, prescinda de toda charla sobre una «transacción» entre distribución y riqueza, ya sean concebidas ambas como valiosas en sí mismas, ya sea como sucedáneos de la igualdad en el bienestar y de la maximización del bienestar» (ibídem, pág. 273).

5. Conclusiones: sobre la injusticia de la pobreza. He tratado de hacer, hasta aquí, un relato de las objeciones de Dworkin a los supuestos valorativos del Análisis Económico del Derecho ${ }^{41}$, objeciones que -aunque no ocupan un puesto central en su dilatada obraconstituyen una de las críticas más extensas y profundas de éstos. Debo admitir, sin embargo, que las críticas de Dworkin resultan en algunos momentos algo oscuras. Creo que vencen a las posiciones fuertes o inmodestas del Análisis Económico (la posición mayoritaria), pero no estoy tan seguro de que tengan el mismo éxito frente a las posiciones moderadas. ¿Admite, al fin, Dworkin que el volumen de riqueza (o un cierto volumen de riqueza) es un ingrediente de la

${ }^{41}$ En Hierro 1993 sobre las objeciones de Dworkin a Posner; en este trabajo sobre las objeciones de Dworkin a Calabresi. 
receta de la Justicia como igualdad? Entiendo que sí, aunque no lo haga de forma explícita y lo considere, quizá, trivial. La tesis de que la riqueza social es un instrumento de valor es presentada en su segunda versión (como ingrediente) en los siguientes términos: «... las mejoras en la riqueza social son ingredientes de un valor social, porque aunque no sirven automáticamente para causar otras mejoras, proveen el material para ellas. Si una sociedad tiene mas riqueza, es mejor porque está en posición de usar aquella riqueza incrementada para reducir la pobreza» (Dworkin 1980, pág. 241). Dworkin nunca afirma de forma explícita que sea ésta una posición teórica aceptable, y creo que la situaría entre aquellas posiciones que «si descansa(n) sólo sobre la pretensión débil de que perseguir la riqueza conducirá algunas veces a otros buenos resultados, entonces el aspecto normativo de la teoría es aburrido y confuso: aburrido porque nadie discutirá la pretensión, y confuso porque la teoría, entonces, debería denominarse, no teoría de la riqueza, sino teoría del hasta-ahora-no-especificado verdadero objetivo que la riqueza, a veces, se supone servir» (ibídem, pág. 250).

Sin embargo, en la segunda parte de la discusión con Calabresi, nos invita a aceptar una teoría de la igualdad que se formula como una receta en la que «la justicia consiste en aquella distribución en la que las personas son tratadas como iguales» (Dworkin 1980/2, pág. 272) y, en otro lugar, admite que «el dinero o su equivalente es útil en la medida en que capacita a alguien para llevar una vida más valiosa, de más éxito, más feliz o más moral» (Dworkin 1980, pág. 245). La cuestión es, entonces, en qué medida esto ocurre y, en la medida en que ocurra, el volumen de riqueza (y su incremento o, al menos, cierto incremento) -sin constituir un valor final- se convierte en un ingrediente necesario aunque no suficiente de la justicia.

Si hiciésemos una interpretación muy restrictiva de las objeciones de Dworkin, tendríamos que llegar a la conclusión de que dos sociedades que tuviesen igual número de miembros (digamos, cien cada una) y en las que se cumpliese estrictamente un mismo principio de igual trato a las personas como resultado del cual la distribución actual de los recursos (en sentido amplio: bienes y derechos) -una vez tomada en cuenta la responsabilidad de cada uno por las propias elecciones ${ }^{42}$ e incluso el principio rawlsiano de diferencia- fuese, por ejemplo, de 10 el 15\%, 45 el 47\%, 35 el 33\% y 10 el 5\%, serían moralmente de igual valor por ser igualmente justas. Y ello aunque la primera tuviese unos recursos totales de 100.000 útiles y la segunda de 1.000 útiles, de modo tal que en la primera incluso los 10 que tienen el $5 \%(0,5 \%=500$ útiles para cada uno $)$ dispusieran de alimento,

${ }^{42}$ Ver Dworkin 1980/2, pág. 270. 
vivienda, educación, sanidad y un razonable ocio cultural, y en la segunda incluso los 35 que tienen el $33 \%(0,9 \%=9,42$ útiles para cada uno $)$ tuviesen apenas recursos para la subsistencia física. No me consta que Dworkin quiera mantener esta tesis ${ }^{43}$. Parece que, simplemente, considera aburrida la teoría de que una mayor riqueza facilita la mejor satisfacción de las necesidades de los miembros de la primera sociedad. Pero -sea que uno se aburra o se divierta con este tema- lo cierto es que, como dice Calabresi, «una mezcla apropiada de eficiencia y distribución es altamente instrumental para, y tiene una estrecha correlación con, conseguir lo que muchos verían como una sociedad justa» (Calabresi 1980, pág. 558) $)^{44}$.

Para una teoría sustantiva -y no meramente procesal- de la justicia que entiende, por ejemplo, que el objetivo de la justicia es satisfacer las necesidades de cada ser humano, como sujeto moral -lo que implica tratar a todas las personas como iguales porque tienen igual valor moral, pero no se reduce a ello- la eficiencia resulta un ingrediente (para aceptar la propuesta de Dworkin), y un ingrediente necesario aunque no suficiente ${ }^{45}$. Y ello no sólo porque la igual satisfacción de las necesidades de cada uno depende sustantivamente de los recursos disponibles más la forma de su distribución, sino también porque la mayor disponibilidad de recursos genera nuevas necesidades, nuevas posibilidades de desarrollo de las capacidades del sujeto

${ }^{43}$ Calabresi 1980, pág. 554 advierte que el lenguaje «innecesariamente provocativo» de Dworkin «will lead someone to misunderstand the piece to mean that efficiency in the production of wealth is irrelevant to a 'just' society»?.

${ }^{44}$ Dworkin ha derivado de su teoría de la justicia como igualdad que el objetivo no es alcanzar una igualdad de bienestar, sino una igualdad de recursos (Dworkin 1993). La igualdad liberal es -dice aquí Dworkin- igualdad de recursos, y no de bienestar (pág. 88) y la justicia no sólo es una cuestión de recursos, sino de recursos iguales (pág. 94). Sostiene así que una porción justa de recursos para cada uno no es una porción grande, sino una porción igual para todos (pág. 172). Con ello Dworkin parece más sensible al ingrediente «recursos», aunque no encuentro todavía una explicación suficientemente clara: porque el problema sigue siendo que los recursos no son algo dado, sino algo que producirnos y podemos incrementar, por lo que una porción justa no es sólo una porción «igual», sino una porción igual y -dadas las circunstancias- suficiente para satisfacer las necesidades básicas. $\mathrm{Y}$, entonces, sería una exigencia de la justicia, bajo mi punto de vista, incrementar los recursos para incrementar las porciones iguales de ellos para satisfacer igualmente aquellas necesidades.

${ }^{45}$ En el mismo sentido ver Albert Calsamiglia 1987, pág. 279: «La eficiencia es una condición necesaria -sin ella no hay justicia- pero no suficiente de justicia».

Una posición distinta -podríamos decir que situada en la «teoría del compromiso»- es la de Santos Pastor (1989, pág. 40) que sostiene que la eficiencia «es uno, entre otros, de los valores que inspiran la organización de las sociedades, y con frecuencia ha de sucumbir frente a la superior importancia de otros», y que «la eficiencia sería el valor social a maximizar, solo si dentro de ella estuviesen comprendidos los demás valores, jerárquicamente organizados...». 
moral que -en la medida en que lo permite una distribución igualitaria- son moralmente candidatas a la consideración de derechos subjetivos ${ }^{46}$. En consecuencia, una Teoría de los derechos (como teoría de la justicia) tiene necesariamente que incluir las consideraciones de eficiencia.

Al fin, creo que la amenaza imperialista de la Economía puede conjurarse: «si los economistas-juristas no cometen el error -como afirma también Calabresi- de pretender demasiado por lo que están haciendo, y si están dispuestos a trabajar en definir y analizar instrumentos bastante buenos que lleven hacia la sociedad justa, los filósofos no debieran estar preocupados» (ibídem, pág. 561) ${ }^{47}$. Pero los filósofos sí debemos preocuparnos de explicar por qué, entre las dos sociedades «justas» del ejemplo, la primera es mejor. Y sólo caben -creo- dos respuestas: bien que la justicia no es la virtud social por excelencia, ya que entre dos sociedades igualmente justas es mejor una más rica, bien que el volumen de riqueza (y su incremento o, al menos, cierto incremento) constituye un ingrediente de la justicia de una sociedad que ha de ser combinado con su distribución igualitaria para satisfacer, en condiciones de igualdad de partida y de compensación de diferencias extremas, las necesidades básicas del hombre como sujeto moral. En este segundo caso, la pobreza resulta ser una injusticia o, al menos, un ingrediente de la injusticia. En todo caso -y para terminar citando, una vez más, a Calabresi- «claramente, la relación entre los instrumentos (eficiencia, distribución) y el objetivo (justicia) necesita ser estudiada» (ibídem, pág. 559).

\section{BIBLIOGRAFÍA}

Ackerman, Bruce A. (1988), Del realismo al constructivismo jurídico, Ariel, Barcelona. (Orig: Reconstructing American Law, Harvard University Press, 1983).

Bisbal, Joaquim (1984), Presentación en Calabresi 1984, págs. 7-17.

${ }^{46}$ Ver Hierro 1982, págs. 57 y ss.

${ }^{47}$ Con ello, además, las propuestas progresistas (liberales, en sentido norteamericano) del sector moderado del Análisis Económico satisfacen el desafio de Horwitz: «como teórico social, uno debe asumir la responsabilidad directa de justificar la justicia de una particular distribución de la riqueza y el poder» (Horwitz 1980, pág. 912). Añade Horwitz que «after twenty years of attempting to claim that the stood above ideology in their devotion to science, the practicioners of law-and-economics have finally been forced to come out of the closet and debate ideology with the rest of us». Creo, sin embargo, haber demostrado que la crítica aquí implícita no puede aplicarse a Calabresi. 
Brenner, Richard (1980), Economics. An Imperialist Science, Journal of Legal Studies, n. ${ }^{\circ}$ 9, págs. 179-188.

Calabresi, Guido (1961), Some Thoughts on Risk Distribution and the Law of Torts, The Yale Law Journal, n. ${ }^{\circ}$ 70, págs. 499-553.

- (1980), About Law and Economics: A letter to Ronald Dworkin, Hofstra Law Review, n. ${ }^{\circ}$ 8, págs. 553-562.

- (1983), The New Economic Analysis of Law: Scholarship, Sophistry, or Self-indulgence? The Proceedings of the British Academy, LXVIII, págs. 85-108.

- (1984), El coste de los Accidentes. Análisis económico y jurídico de la responsabilidad civil, Ariel, Barcelona. (Orig: The Cost of Accidents. A Legal and Economic Analysis, Yale University Press, New Haven, 1970).

- (1985) Los límites de algunos análisis no económicos del Derecho, Anuario de Filosofía del Derecho, n. ${ }^{\circ} 2$ (nueva época), págs. 221-228.

- (1991), The Pointlessness of Pareto: Carrying Coase Further, The Yale Law Journal, n.o 100, págs. 1.211-1.237.

Calabresi, Guido y Hirschoff, Jon T. (1972), Toward a Test for Strict Liability in Torts, The Yale Law Journal, n. ${ }^{\circ} 81$ (reproducido en Kuperberg-Beitz 1983, págs. 154-184).

Calabresi, Guido y Melamed, A. Douglas (1972), Property Rules, Liability Rules, and Inalienability: one View of the Cathedral, Harvard Law Review, n. 85 (reproducido en Kuperberg-Beitz 1983, págs. 41-80, por donde se cita).

Calsamiglia, Albert (1987), Eficiencia y Derecho, Doxa, Cuadernos de Filosofía del Derecho, n. ${ }^{\circ} 4$, págs. 267-287.

Coase, Ronald H. (1960), The Problem of Social Cost, The Journal of Law and Economics, n. 3 (reproducido en Kuperberg-Beitz 1983, págs. 13-40) (hay traducción española: El problema del coste social, Hacienda Pública Española, n. $\left.{ }^{\circ} 68,1981\right)$.

Chiassoni, Pierluigi (1990), Analisi economica del diritto, formularismo, realismo, Analisi e Diritto, págs. 29-76.

Durán y Lalaguna, Paloma (1992), Una aproximación al análisis económico del Derecho, Edit. Comares, Granada.

Dworkin, Ronald (1980), Is Wealth a Value?, The Journal of Legal Studies, n. ${ }^{\circ}$ 9, págs. 191-226 (reproducido en Dworkin 1985, Capítulo 12, por donde se cita).

- (1980/2) Why Efficiency? Hofstra Law Review, n. ${ }^{\circ}$ 8, págs. 563-590 (reproducido en Dworkin 1985, Capítulo 13, por donde se cita), (reproducido también en Kuperberg-Beitz 1983, págs. 123-140, donde falta toda la primera parte dedicada a Calabresi).

- (1985), A Matter of Principle, Harvard University Press, Cambridge (Mass.).

- (1986), Law's Empire, Harvard University Press, Cambridge (Mass.)

(1993), Ética privada e igualitarismo politico, Edic. Paidós (I.C.E./U.A.B.), Barcelona. (Orig: Foundations of Liberal Equality, University of Utah Press, Salt Lake City (Utah).

Hierro, Liborio L. (1982), ¿Derechos humanos o necesidades humanas? Problemas de un concepto, Sistema, n. ${ }^{\circ} 46$, págs. 45-6 1 . 
- (1993), Contra el imperio de la riqueza (Dworkin versus Posner). En Ronald Dworkin. Estudios en su homenaje, Revista de Ciencias Sociales (Universidad de Valparaíso), n. ${ }^{\circ}$ 38, págs. 383-411.

Horwitz, Morton J. (1980), Law and Economics: Science or Politics?, Hoftstra Law Reviev, n. ${ }^{\circ} 8$, págs. 905-912.

Johnsen, D. Bruce (1986), Wealth is Value, The Journal of Legal Studies, n. ${ }^{\circ}$ 15, págs. 263-288.

Kronman, Anthony T. (1980), Wealth Maximization as a Normative Principle, The Journal of Legal Studies, n. ${ }^{\circ}$ 9, págs. $227-242$.

Kuperberg, Mark y Beitz, Charles (1983), Law, Economics and Philosophy. A Critical Introduction with Applications to the Law of Torts, Rowman \& Allanheld, New Jersey.

Mercado, Pedro (1994), El análisis económico del Derecho. Una reconstrucción teórica, Centro de Estudios Constitucionales, Madrid.

Paz Ares, Cándido (1981), La economía política como jurisprudencia racional. (Aproximación a la Teoría económica del Derecho). Anuario de Derecho Civil, págs. 601-707.

Pastor, Santos (1989), Sistema jurídico y Economía. Una introducción al análisis económico del Derecho, Tecnos, Madrid.

Polinski, A. Mitchell (1985), Introducción al análisis económico del Derecho, Ariel, Barcelona. (Orig: An Introduction to Law and Economics, 1983).

Posner, Richard A. (1980), The Ethical and Political Basis of the Efficiency Norm in Common Law Adjudication, Hofstra Law Review, n. ${ }^{\circ} 8$ (reproducido en Kuperberg-Beitz 1983, págs. 81-101, por donde se cita).

- (1990), The Problems of Jurisprudence, Harvard University Press, Cambridge (Mass.).

- (1992), Legal Reasoning form the Top-Dow and from the Bottom-Up: the Question of Unenumerated Constitutional Rights, The University of Chicago Law Review, n. ${ }^{\circ} 59$, págs. 433-450.

Torres López, Juan (1987), Análisis económico del Derecho. Panorama doctrinal, Tecnos, Madrid. 
$\triangle$ 